\title{
An Assessment of the Influence of Dental Porcelain Slurry Preparation on Flexural Strength of Different Feldspathic Porcelains
}

\author{
Abdulmonem Alshihri ${ }^{1,2}$, Nadin Al-Haj Husain ${ }^{1,3}$, Kai Vogeler ${ }^{1}$ and Mutlu Özcan ${ }^{1, *}$ (1) \\ 1 Division of Dental Biomaterials, Center of Dental Medicine, Clinic for Reconstructive Dentistry, University of \\ Zurich, 8032 Zurich, Switzerland; monem.alshihri@post.harvard.edu (A.A.); \\ nadin.al-haj-husain@zmk.unibe.ch (N.A.-H.H.); info@enamel.ch (K.V.) \\ 2 Department of Prosthetic Dental Sciences, College of Dentistry, King Saud University, \\ Riyadh 11451, Saudi Arabia \\ 3 Department of Reconstructive Dentistry and Gerodontology, School of Dental Medicine, University of Bern, \\ 3010 Bern, Switzerland \\ * Correspondence: mutlu.ozcan@zzm.uzh.ch; Tel.: +41-44-6345-600; Fax: +41-44-6344-305
}

Citation: Alshihri, A.; Al-Haj Husain, N.; Vogeler, K.; Özcan, M. An Assessment of the Influence of Dental Porcelain Slurry Preparation on Flexural Strength of Different Feldspathic Porcelains. Appl. Sci. 2021, 11, 9385. https://doi.org/ 10.3390/app11209385

Academic Editor: Ivana Miletić

Received: 23 September 2021

Accepted: 6 October 2021

Published: 9 October 2021

Publisher's Note: MDPI stays neutral with regard to jurisdictional claims in published maps and institutional affiliations.

Copyright: (C) 2021 by the authors Licensee MDPI, Basel, Switzerland. This article is an open access article distributed under the terms and conditions of the Creative Commons Attribution (CC BY) license (https:// creativecommons.org/licenses/by/ $4.0 /)$.
Abstract: Chipping remains a big challenge during the clinical application of glass ceramics in dentistry. The fabrication procedure used affects the mechanical properties of dental feldspathic porcelain and is associated with technical failures. This study aimed to compare the effect of the use of manufacturers' liquids versus $\mathrm{H}_{2} \mathrm{O}$ on the flexural strength of glass ceramics. Specimens $(n=120$, $n=15$ per group) $(25 \times 4 \times 1.2 \mathrm{~mm})$ were obtained using four porcelain powders (Creation CC, IPS InLine, Noritake EX-3, and Vita VM 13). Four groups were produced using porcelain powder and modeling liquid, and four groups using distilled water. The specimens were fired, sintered, and polished. Flexural strength was measured using a universal testing machine. Statistical analyses were conducted using post hoc Tukey's, two-way ANOVA, and Weibull analysis. Flexural strength values (mean $\pm \mathrm{SD}$ ) of the ceramic-manufacturer's liquid mixture ranged between $67.2 \pm 10.2$ and $85.8 \pm 12.8 \mathrm{MPA}(\mathrm{NR}<\mathrm{VT}<\mathrm{IV}<\mathrm{CR}$ ), while flexural strength values of the ceramic-water mixture were between $72.2 \pm 6.9$ and $95.2 \pm 12 \mathrm{MPA}(\mathrm{CR}<\mathrm{NR}<\mathrm{VT}<\mathrm{IV})$. While the choice of the ceramic type significantly affected flexural strength, the use of water vs. manufacturers' liquid showed in almost all cases no significance. To achieve better flexural strength results, InLine should be used with distilled water mixtures, while all ceramic powders except for Noritake can be used with the manufacturer's liquid mixtures.

Keywords: ceramic; feldspathic porcelain; flexural strength; lithium disilicate; liquid

\section{Introduction}

Dental feldspathic porcelains are silica-based ceramics that consist of an amorphous glassy matrix (potassium aluminosilicate) with dispersed leucite particles [1,2]. The use of feldspathic porcelain in dentistry has been associated with superior aesthetics, high wear resistance, and biocompatibility [3-5]. Various porcelain-based restorations (e.g., PFM and veneers) have demonstrated safe treatment outcomes, with long-term survival rates. However, porcelain fracture or chipping were among the most reported complications [5]. Fabrication of dental porcelain, especially feldspathic veneering, is technique-sensitive, in addition to the material's brittle nature and low strength $[5,6]$; therefore, thorough and precise adherence to technical fabrication protocol is crucial to clinical performance [7-9]. Moreover, several manufacturing factors can influence the final porcelain product, such as ceramic powder particle size, distribution, and chemical composition $[9,10]$. During the fabrication of porcelain prostheses, a mix of porcelain powder and liquid is made to produce the working ceramic slurry, paste for layering, and veneering to the full counter of the restoration. Ceramic slurry paste preparation conditions, ratios, and characteristics can 
affect the physicomechanical properties, and therefore clinical outcomes [7-10]. As dental ceramic manufacturers and technicians have different recommendations and techniques on handling ceramics, it is not necessarily proven if slurry paste preparation is clinically advantageous to the sintered porcelain quality. For instance, Zhang et al. reported that the porcelain powder/liquid ratio influenced the density and total porosity of ceramic specimens [7]. Furthermore, the effect of porcelain powder-liquid mixing technique on bi-flexural strength was investigated. The results showed that when porcelain powder was incrementally mixed into liquid, a higher bi-flexural strength was achieved [8]. For proper porcelain condensation, porcelain powder has its particles distributed in a characterized size to yield a maximum density of particles. Such variation in particle size is critical to slurry application and sintering in terms of volumetric changes, and structural properties $[9,10]$. In the laboratory phase of porcelain slurry preparation, fine porcelain powder is mixed with liquid to form porcelain slurry paste. Dental technicians use different techniques to mix porcelain powder and liquid to produce porcelain slurry paste. Some technicians mix the porcelain powder with its own manufacturer's porcelain modeling liquid. On the other hand, distilled water has been used with porcelain powder to produce porcelain slurry [10-12]. There is limited knowledge on the effect of using different liquids to mix with porcelain powder. Therefore, the aim of this study was to investigate the effect of using different liquids-distilled water and commercial porcelain liquids—on the flexural strength of sintered porcelain blocks. The null hypothesis tested was that mixing ceramic powders, with either the corresponding manufacturer's liquid or water, would not have a significant effect on the flexural strength of leucite ceramics.

\section{Materials and Methods}

\subsection{Specimen Preparation}

Four commercially available dental porcelain powders (Creation CC (Creation Willi Geller International GmbH, Meininge, Austria), IPS InLine (Ivoclar Vivadent, Schaan, Liechtenstein), Noritake EX-3 (Kuraray Noritake Dental Inc., Tokyo, Japan), and Vita VM 13 (VITA Zahnfabrik H. Rauter GmbH \& Co. KG, Bad Sackingen, Germany) were tested in this study (Table 1).

Table 1. Chemical compositions of different ceramics and related modeling liquids, according to manufacturers. Sources: https://www.ivoclarvivadent.com (accessed on: 31 July 2019); https://www.creation-willigeller.com (accessed on: 31 July 2019); https:/ /apollonia-indent.net (accessed on: 31 July 2019); https:/ / www.kuraraynoritake.e (accessed on: 31 July 2019) and https:/ / www.vita-zahnfabrik.com (accessed on: 31 July 2019).

\begin{tabular}{|c|c|c|c|}
\hline Brand & Manufacturer & Ceramic Chemical Composition & $\begin{array}{l}\text { Ceramic Modeling Liquid } \\
\text { Chemical Composition } \\
\text { (Weight \%) }\end{array}$ \\
\hline $\begin{array}{l}\text { Creation CC } \\
\text { (C) }\end{array}$ & $\begin{array}{l}\text { Creation Willi Geller } \\
\text { International GmbH, } \\
\text { Meininge, Austria }\end{array}$ & 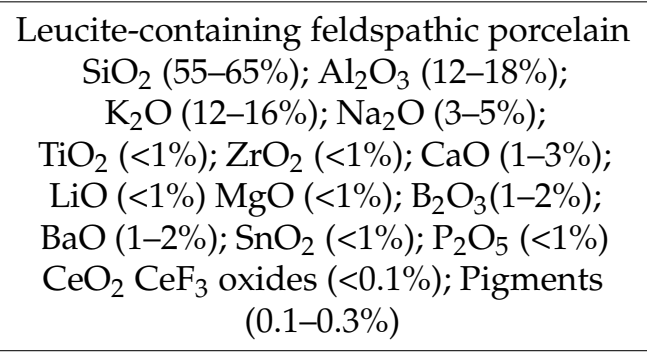 & $\begin{array}{l}\text { Purified water }(>99 \%) ; \\
\text { Propylene glycol }(0-4 \%) \text {, } \\
\text { Zinc chloride }(<0.1 \%)\end{array}$ \\
\hline $\begin{array}{l}\text { IV IPS InLine } \\
\text { (IV) }\end{array}$ & $\begin{array}{c}\text { Ivoclar Vivadent, } \\
\text { Schaan, Liechtenstein }\end{array}$ & $\begin{array}{c}\text { Leucite-containing feldspathic porcelain } \\
\mathrm{SiO}_{2}(59.5-65.5 \%) ; \mathrm{Al}_{2} \mathrm{O}_{3}(13.0-18.0 \%) ; \\
\mathrm{K}_{2} \mathrm{O}(10.0-14.0 \%) ; \mathrm{Na}_{2} \mathrm{O}(4.0-8.0 \%) ; \\
\text { other oxides }(<4.0 \%) ; \text { pigment }(<2.0 \%)\end{array}$ & $\begin{array}{c}\text { Water and/or glycol } \\
90-99 \%, \\
\text { polymer }(1-10 \%)\end{array}$ \\
\hline
\end{tabular}


Table 1. Cont.

\begin{tabular}{|c|c|c|c|}
\hline Brand & Manufacturer & Ceramic Chemical Composition & $\begin{array}{l}\text { Ceramic Modeling Liquid } \\
\text { Chemical Composition } \\
\text { (Weight \%) }\end{array}$ \\
\hline $\begin{array}{l}\text { Noritake super } \\
\text { porcelain EX } \\
\qquad(n)\end{array}$ & $\begin{array}{l}\text { Kuraray Noritake } \\
\text { Dental Inc., Tokyo, } \\
\text { Japan }\end{array}$ & $\begin{array}{c}\text { Leucite-containing feldspathic porcelain } \\
\mathrm{SiO}_{2}(64.5 \%) ; \mathrm{Al}_{2} \mathrm{O}_{3}(14.4 \%) \\
\mathrm{CaO}(<1.0 \%) ; \mathrm{MgO}(<1.0 \%) \\
\mathrm{K}_{2} \mathrm{O}(8.7 \%) ; \mathrm{Na}_{2} \mathrm{O}(9.2 \%) \\
\mathrm{Li}_{2} \mathrm{O}(<1.0 \%) ; \mathrm{B}_{2} \mathrm{O}_{3}(0 \%) ; \\
\text { pigments }(<1 \%)\end{array}$ & $\begin{array}{c}\text { Polyethyleneglycol } \\
\text { Water } \\
\text { Additives } \\
\% \text { is not disclosed by the } \\
\text { manufacturer }\end{array}$ \\
\hline $\begin{array}{l}\text { VITA VM13 } \\
\text { (V) }\end{array}$ & $\begin{array}{l}\text { VITA Zahnfabrik H. } \\
\text { Rauter } \\
\text { GmbH \& Co. KG, Bad } \\
\text { Sackingen, Germany }\end{array}$ & $\begin{array}{l}\text { Leucite-containing feldspathic porcelain } \\
\mathrm{SiO}_{2}(55-72 \%) ; \mathrm{Al}_{2} \mathrm{O}_{3}(12-16 \%) ; \\
\mathrm{K}_{2} \mathrm{O}(8-10 \%) ; \mathrm{Na}_{2} \mathrm{O}(4-6 \%) ; \mathrm{TiO}_{2}(<1 \%) ; \\
\mathrm{CeO}_{2}(<1 \%) ; \mathrm{ZrO}_{2}(<1 \%) ; \mathrm{CaO}(1-2 \%) ; \\
\mathrm{B}_{2} \mathrm{O}_{3}(1-2 \%) ; \mathrm{BaO}(1-3 \%) ; \mathrm{SnO}_{2}(<1 \%) ; \\
\mathrm{Mg} \text {, } \mathrm{Fe} \text {, and } \mathrm{P} \text { oxides }(<0.1 \%)\end{array}$ & $\begin{array}{l}\text { Purified water }(>99 \%) \\
\text { Inorganic components } \\
\qquad(<1 \%)\end{array}$ \\
\hline
\end{tabular}

The porcelain powders used were composed of dentin-feldspathic porcelain containing leucite crystals. In preparation for firing, $0.7 \mathrm{~g}$ of each porcelain powder was mixed once with distilled water (15 specimens/porcelain type), and once with their corresponding porcelain's modeling liquid (15 specimens/porcelain type). A homogeneous slurry was obtained according to manufacturer's recommendations and inserted, in one increment, into a metallic matrix. The mold was overfilled with slurry, and condensed by one dental technician (K.V.) on a vibrating table for $90 \mathrm{~s}$. The slurry was then transferred into standardized cylindrical metallic pistons ( $25 \mathrm{~mm}$ length, $4 \mathrm{~mm}$ width, and $1.2 \mathrm{~mm}$ thickness), and absorbent paper was used to remove excess liquid. The disc-shaped specimens were thereafter removed from the matrix and placed in specific furnaces (Vacumat 40, VITA Zahnfabrik) for firing cycles, according to the manufacturer's recommendations (Table 2).

Table 2. Firing procedures of the dental ceramics tested. ST: starting temperature, DT: drying time, FT: final temperature, TRI: temperature rate of increase, HT: holding time.

\begin{tabular}{ccccccc}
\hline Ceramic & ST $\left({ }^{\circ} \mathbf{C}\right)$ & $\begin{array}{c}\text { DT } \\
(\mathbf{m i n})\end{array}$ & $\begin{array}{c}\text { TRI } \\
\left({ }^{\circ} \mathbf{C} / \text { min }\right)\end{array}$ & $\begin{array}{c}\text { Vacuum } \\
\text { Pressure }\end{array}$ & $\begin{array}{c}\text { FT } \\
\left({ }^{\circ} \mathbf{C}\right)\end{array}$ & $\begin{array}{c}\text { HT } \\
(\mathbf{m i n})\end{array}$ \\
\hline $\mathrm{CR}$ & 580 & 6 & 55 & Yes & 920 & 1 \\
\hline $\mathrm{IV}$ & 403 & 4 & 60 & Yes & 910 & 1 \\
\hline $\mathrm{NR}$ & 400 & 8 & 65 & Yes & 980 & 1 \\
\hline $\mathrm{VT}$ & $400{ }^{\circ} \mathrm{C}$ & 6 & 55 & Yes & $880{ }^{\circ} \mathrm{C}$ & 1 \\
\hline
\end{tabular}

After the sintering process, the surface of each specimen was manually polished sequentially, using up to \#600-grit silicon-carbide paper (Struers, Willich, Germany) under water-cooling, until a flat surface was obtained. Dimensions were verified using a digital micrometer (Mitutoyo, Kanagawa, Japan). The three dimensions (length, width, and height) of each specimen were measured. Specimens were inspected for cracks and replaced if needed. The final dimensions of the discs were $25 \mathrm{~mm}$ in length, $4 \mathrm{~mm}$ in width, and $1.2 \mathrm{~mm}$ in thickness (ISO 6872) [1].

\subsection{Flexural Testing}

Upon production of fifteen ceramic discs per group ( $n=120,8$ groups), flexural strength measurements were conducted according to ISO 6872:2015 [1]. A three-point bending test was performed using a universal testing machine (Universal Testing Machine, ZwickRoell, Ulm, Germany) at a crosshead speed of $1 \mathrm{~mm} / \mathrm{min}$ on a $10 \mathrm{~mm}$ span. Each specimen was loaded until ceramic failure occurred, and fracture load data were obtained. 
The recorded values of the fracture load were used to calculate the biaxial flexural strength. The expected flexural strength ( $\sigma$ in MPa) of a rectangular sample under a load in a threepoint bending setup is calculated using the following formula $[13,14]: \sigma=3 \cdot \mathrm{F}_{\max } \cdot \mathrm{L} / 2 \cdot \mathrm{b} \cdot \mathrm{d}^{2}$, where $\mathrm{F}_{\max }$ is the maximum force (Newton) applied to achieve fracture of the specimen.

\subsection{Statistical Analysis}

Statistical analyses were performed using the Social Sciences statistical software package (SPSS Software V.20, Chicago, IL, USA). Data on the flexural strength parameters of 4 different ceramic systems (Noritake, IV-Line, Creation and Vita) with two different liquids (manufacturer's liquid and $\mathrm{H}_{2} \mathrm{O}$ ) were analyzed using two- way ANOVA comparisons. Interaction terms were analyzed using Tukey's tests. In addition, maximum likelihood estimation without a correction factor was used for a 2-parameter Weibull distribution. Weibull distribution was performed to interpret the predictability and reliability of adhesion (Minitab Software V.16, State College, PA, USA). A value of $p<0.05$ was considered statistically significant in all tests. No ethical approval or informed consent was needed for this study.

\section{Results}

The flexural strength values (Mean $\pm \mathrm{SD}$ ) of the ceramic-manufacturers' liquid mixtures ranged between $67.2 \pm 10.2$ and $85.8 \pm 12.8 \mathrm{MPA}(\mathrm{NR}<\mathrm{VT}<\mathrm{IV}<\mathrm{CR})$, while the flexural strength values (mean $\pm \mathrm{SD}$ ) of the ceramic-water mixtures were between $72.2 \pm 6.9$ and $95.2 \pm 12.7 \mathrm{MPA}(\mathrm{CR}<\mathrm{NR}<\mathrm{VT}<\mathrm{IV})$ (Table 3$)$.

Table 3. The mean flexural values ( $\mathrm{MPa} \pm$ standard deviations) of IV, NR, VT, and CR, and their related modeling liquids. $95 \%$ confidence interval of mean values of IV, NR, VT, and CR, and their related modeling liquids. The same superscript lowercase letters in the same column indicate no significant differences and uppercase letters based on the experimental group $(p<0.05)$.

\begin{tabular}{|c|c|c|c|c|}
\hline $\begin{array}{l}\text { Ceramic } \\
\text { Type }\end{array}$ & $\begin{array}{c}\text { Flexural Strength (Mean } \pm \text { SD) } \\
\text { Water }(W)\end{array}$ & $\begin{array}{c}\text { Flexural Strength (Mean } \pm \text { SD) } \\
\text { Liquid (L) }\end{array}$ & $\begin{array}{c}\text { Min-Max FS } \\
\text { (95\% CI) } \\
\text { Water (W) }\end{array}$ & $\begin{array}{c}\text { Min-Max FS } \\
\text { (95\% CI) } \\
\text { Liquid (L) }\end{array}$ \\
\hline CR & $72.2 \pm 6.9^{\mathrm{a}, \mathrm{A}}$ & $85.8 \pm 12.8^{\mathrm{a}, \mathrm{A}}$ & $\begin{array}{l}67.3-107.9 \\
(68.5-75.9)\end{array}$ & $\begin{array}{l}63.1-86.7 \\
(79.0-92.6)\end{array}$ \\
\hline IV & $95.2 \pm 12.7^{\mathrm{b}, \mathrm{c}, \mathrm{B}}$ & $83.1 \pm 16.9^{\mathrm{a}, \mathrm{c}, \mathrm{B}}$ & $\begin{array}{c}68.5-121.1 \\
(88.4-102.1)\end{array}$ & $\begin{array}{l}45.6-132.8 \\
(74.1-92.1)\end{array}$ \\
\hline NR & $76.3 \pm 6.3^{\mathrm{a}, \mathrm{d}, \mathrm{C}}$ & $67.2 \pm 10.2^{b, d, e, C}$ & $\begin{array}{c}45.9-89.0 \\
(72.9-79.7)\end{array}$ & $\begin{array}{l}38.5-76.7 \\
(61.8-72.6)\end{array}$ \\
\hline VT & $81.7 \pm 12.1^{\mathrm{a}, \mathrm{c}, \mathrm{D}}$ & $79.7 \pm 14.6^{\mathrm{a}, \mathrm{c}, \mathrm{e}, \mathrm{D}}$ & $\begin{array}{l}56.7-108.7 \\
(75.3-88.1)\end{array}$ & $\begin{array}{l}60.2-98.9 \\
(71.9-87.5)\end{array}$ \\
\hline
\end{tabular}

When the $\mathrm{H}_{2} \mathrm{O}$ mixture of each ceramic system was compared to its corresponding manufacturer's liquid mixture, there were no significant differences for all four ceramic types.

Within the $\mathrm{H}_{2} \mathrm{O}$ mixtures, IV showed significantly higher flexural strength values compared to the other ceramics; namely, Creation $(p=0.00007)$, Noritake $(p=0.006)$, and Vita $(p=0.018)$. Within the liquid mixtures, NR had the significantly lowest flexural strength values compared to the other ceramics, namely Creation $(p=0.003)$ and InLine $(p=0.0431)$, and no difference with Vita $(p=0.122)$ (Figures 1-3).

When flexural strength was evaluated, Weibull distribution presented lower shape values for the groups IV (8.3 vs. 4.3$)$, VT (9.0 vs. 6.0,) and CR (11.0 vs. 7.8$)$ when mixed with $\mathrm{H}_{2} \mathrm{O}$ compared to their corresponding liquids, and higher shape values for the group NR (10.0 vs.10.6). Weibull analysis showed more reliable flexural strength for the groups IV, VT, and CR when mixed with $\mathrm{H}_{2} \mathrm{O}$ compared to their corresponding liquids (Figure 4). 


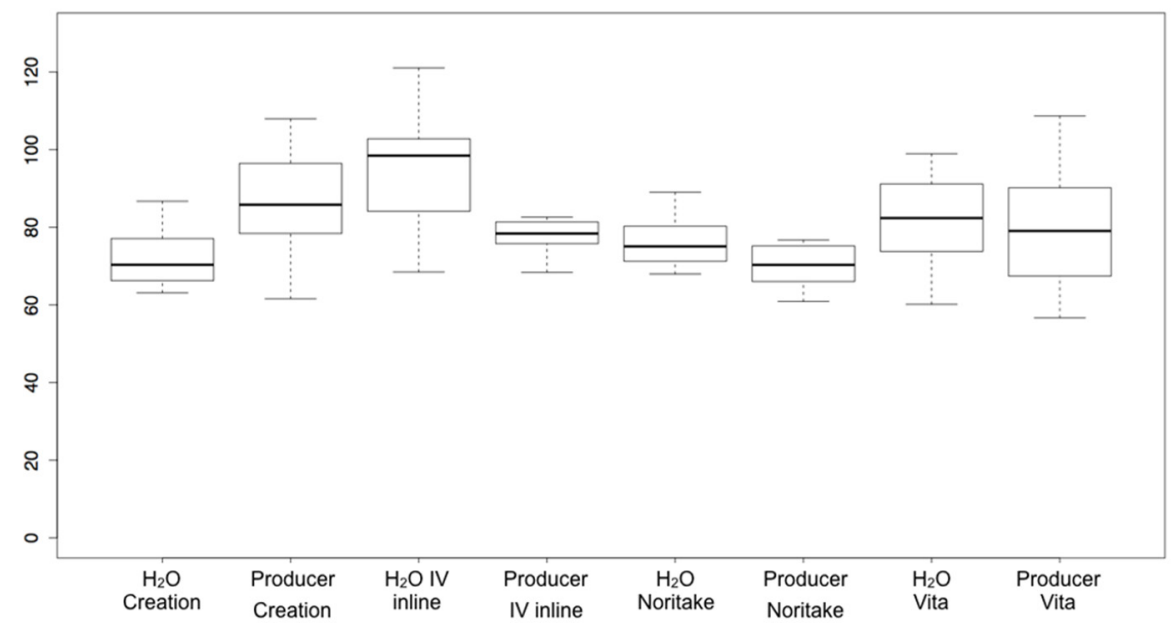

Figure 1. Boxplot-best of the groups $\mathrm{CR}, \mathrm{IV}, \mathrm{NR}$, and VT, mixed with $\mathrm{H}_{2} \mathrm{O}$ or their corresponding modeling liquids.

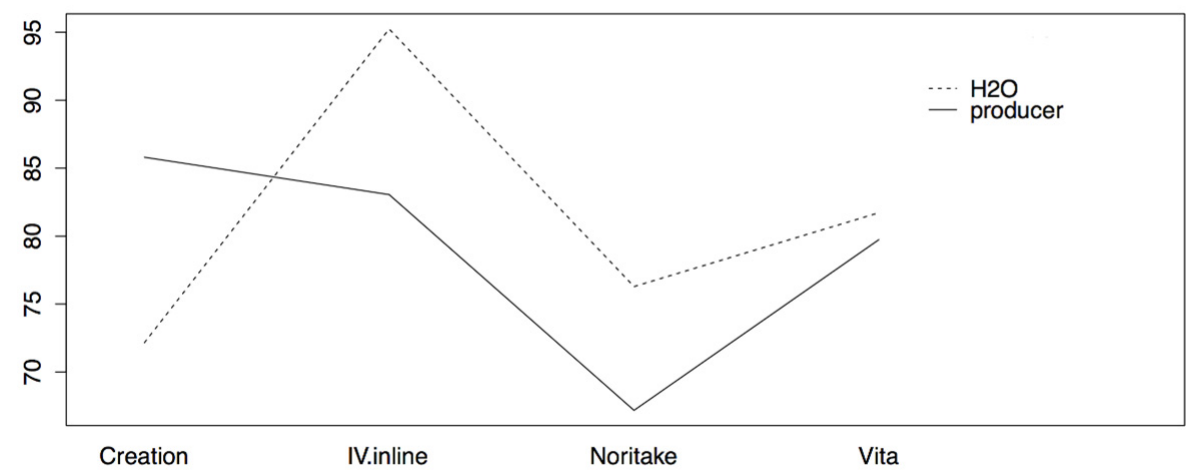

Figure 2. Mean of MPA interaction of the various tested ceramic groups CR, IV, NR, and VT, mixed with $\mathrm{H}_{2} \mathrm{O}$ or their corresponding modeling liquids.

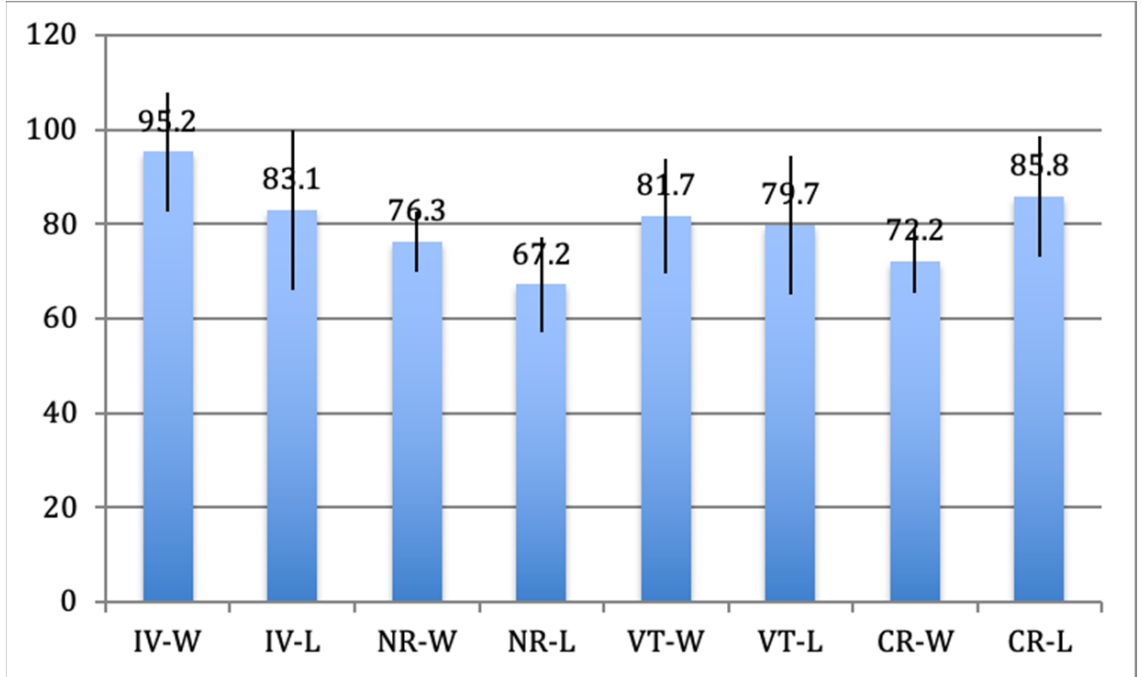

Figure 3. Mean and standard deviation for the various tested ceramics groups CR, IV, NR, and VT, mixed with $\mathrm{H}_{2} \mathrm{O}$ or their corresponding modeling liquids. 




Figure 4. Weibull parameters (shape and scale) of the various tested ceramics groups CR, IV, NR, and $\mathrm{VT}$, mixed with $\mathrm{H}_{2} \mathrm{O}$ or their corresponding modeling liquids.

\section{Discussion}

This study was performed to investigate possible differences in flexural strength of different ceramic types when ceramic slurry was prepared either with distilled water, or manufactured modeling liquid. The effect of mixing ceramic powder with liquid on clinical performance during the procedure of ceramic restoration preparation is unknown. Our findings demonstrated comparable outcomes in the flexural strength of each ceramic, made either with distilled water slurry or using the manufacturers' modeling liquid. However, our results showed that different ceramics produced with distilled water had significantly higher flexural strength in the IV-water group. Conversely, among ceramics prepared using manufacturers' modelling liquids, the NRL group had significantly lower flexural strength compared to others. Similarly, Sinmazişik et al. [11] reported a non-significant statistical difference between bi-flexural strength of porcelains prepared with either distilled water or manufacturers' modeling liquid. Within this non-significant difference, a $5 \%$ increase in bi-flexural strength was found when porcelains were prepared with modeling liquids. Our study, however, showed variations, with both increases and decreases in flexural strength achieved by both mixing liquids. These differences in findings, although not statistically significant, could be attributed to multiple factors, such as the difference in brands used in both studies, despite porcelain type similarity [11]. Moreover, Sinmazısik et al. reported results similar to our study's, where significant differences were found between bi-flexural strength of tested ceramics, irrespective of the mixing liquids [11]. Nonetheless, all flexural strength values measured in this study are well above the ISO 6872 standard, with a minimum requirement of $50 \mathrm{MPa}$ for ceramics used in metal substructures [13].

Optimizing the technical aspects of porcelain-based restoration aligns with maximizing its clinical performance and success. Clinically, chipping and fracturing of ceramic veneers are among the most frequent technical complications reported [2,3]. Of relevance, technical aspects of ceramic fabrication could influence its mechanical properties. Zhang et al. examined the effect of different power/liquid ratios on porosity and translucency [7]. It was found that both the liquid mixing ratio and porcelain type had a significant effect on resulting porosity and apparent density, and therefore influenced the mechanical characteristics of tested porcelains [14]. In that respect, differences in densities between the manufacturers' modeling liquids $\left(0.9-0.94 \mathrm{~g} / \mathrm{cm}^{3}\right)$ and distilled water $\left(p=1.0 \mathrm{~g} / \mathrm{cm}^{3}\right)$ lead to variations in mixed slurry density, which consequently leads to different porcelain outcomes. Different studies showed increased density and decreased porosity when modeling liquid was used for porcelain slurry preparation. Zhang et al. [15] investigated 
the effects of various water powder/liquid and powder/water ratios and attributed this to the fact that a larger volume of modeling liquid was needed compared to distilled water, to achieve similar weight in the tested groups, which resulted in an increase in the density [14]. Thus, it increased the wetting of porcelain powder with modeling liquid and, therefore, the density. It was concluded that the observed increase in flexural strengths could be a result of reduced porosity and improved density of porcelain specimens [11,15]. Flexural strength values might be influenced by material composition and microstructure, as all tested materials yielded comparable $\mathrm{SiO}_{4}$ values ranging between $55 \%$ and $72 \%$, and the microstructure of glass ceramics, e.g., crystal size, crystal volume, and homogeneous distribution, influences the mechanical properties and crack propagation matter of the material [7]. However, previous investigations using XDR and SEM showed that neither distilled water or manufacturer's recommended modelling liquid had any effect in the resultant final microstructure [11]. This finding is also in accordance with the results of this study, as flexural strength was comparable. A limitation of this in vitro study is that ageing procedures simulating the human oral environment were not used. Therefore, future research should investigate the effect of ageing upon the longevity of ceramic mixtures containing both different veneering liquids, and $\mathrm{H}_{2} \mathrm{O}$.

\section{Conclusions}

From this study, the following could be concluded:

- The flexural strength of the ceramic Creation was better when mixed with the corresponding producer's liquid while all other tested ceramics (Noritake, InLine, and Vita) achieved higher flexural results when mixed with $\mathrm{H}_{2} \mathrm{O}$.

- When the commercial modeling liquids were used, NRL resulted in a significantly lower flexural strength.

- When different ceramic powders were mixed with distilled water, IV showed significantly highest flexural strength.

- Overall, regardless of which mixing liquid was used, within each ceramic type, there was no statistically significant difference in flexural strength.

Author Contributions: Conceptualization, K.V. and M.Ö.; methodology, K.V. and M.Ö.; software, K.V. and M.Ö.; validation, K.V. and M.Ö.; formal analysis, M.Ö.; investigation, K.V. and M.Ö.; resources, K.V. and M.Ö.; data curation, K.V. and M.Ö.; writing-original draft preparation, A.A., N.A.-H.H. and M.Ö.; writing-review and editing, A.A., N.A.-H.H. and M.Ö.; visualization, A.A., N.A.-H.H. and M.Ö.; supervision, N.A.-H.H. and M.Ö.; project administration, M.Ö.; funding acquisition, M.Ö. All authors have read and agreed to the published version of the manuscript.

Funding: This research received no external funding.

Institutional Review Board Statement: Not applicable.

Informed Consent Statement: Not applicable.

Conflicts of Interest: The authors declare no conflict of interest.

\section{References}

1. International Organization for Standardization. Dentistry-Ceramic Materials, International Organization for Standards. ISO 6872. 2015. Available online: https:/ / www.iso.org/standard/59936.html (accessed on 30 November 2020).

2. Kelly, J.R.; Nishimura, I.; Campbell, S.D. Ceramics in dentistry: Historical roots and current perspectives. J. Prosthet. Dent. 1996, 75, 18-32. [CrossRef]

3. Sadowsky, S.J. An overview of treatment considerations for esthetic restorations: A review of the literature. J. Prosthet. Dent. 2006, 96, 433-442. [CrossRef] [PubMed]

4. Messer, R.L.; Lockwood, P.E.; Wataha, J.C.; Lewis, J.B.; Noris, S.; Bouillaguet, S. In vitro cytotoxicity of traditional versus contemporary dental ceramics. J. Prosthet. Dent. 2003, 90, 452-458. [CrossRef]

5. Morimoto, S.; Albanesi, R.B.; Sesma, N.; Agra, C.M.; Braga, M.M. Main clinical outcomes of feldspathic porcelain and glassceramic laminate veneers: A systematic review and meta-analysis of survival and complication rates. Int. J. Prosthodont. 2016, 29, 38-49. [CrossRef] [PubMed] 
6. Jung, Y.G.; Wuttiphan, S.; Peterson, I.M.; Lawn, B.R. Damage modes in dental layer structures. J. Dent. Res. $1999,78,887-897$. [CrossRef] [PubMed]

7. Zhang, Y.; Griggs, J.A.; Benham, A.W. Influence of powder/liquid mixing ratio on porosity and translucency of dental porcelains. J. Prosthet. Dent. 2004, 91, 128-135. [CrossRef] [PubMed]

8. Pelaez-Vargas, A.; Dussan, J.A.; Restrepo-Tamayo, L.F.; Paucar, C.; Ferreira, J.A.; Monteiro, F.J. The effect of slurry preparation methods on biaxial flexural strength of dental porcelain. J. Prosthet. Dent. 2011, 105, 308-314. [CrossRef]

9. Rasmussen, S.T.; Ngaji-Okumu, W.; Boenke, K.; O’Brien, W.J. Optimum size distribution for reduced sintering shrinkage of a dental porcelain. Dent. Mater. 1997, 13, 43-50. [CrossRef]

10. Philips, R.W. Dental ceramics. In Skinner's Science of Dental Materials, 12th ed.; Kenneth, J.A., Ed.; Elsevier: Amsterdam, The Netherlands, 1991; Volume 18, pp. 418-473.

11. Sinmazişik, G.; Oveçoğlu, M.L. Physical properties and microstructural characterization of dental porcelains mixed with distilled water and modeling liquid. Dent. Mater. 2006, 22, 735-745. [CrossRef] [PubMed]

12. Galhano, G.A.; Valandro, L.F.; De Melo, R.M.; Scotti, R.; Bottino, M.A. Evaluation of the flexural strength of carbon fiber-, quartz fiber-, and glass fiber-based posts. J. Endod. 2005, 31, 209-211. [PubMed]

13. D'Arcangelo, C.; Cinelli, M.; De Angelis, F.; D'Amario, M. The effect of resin cement film thickness on the pullout strength of a fiber-reinforced post system. J. Prosthet. Dent. 2007, 98, 193-198. [CrossRef]

14. Cheung, K.C.; Darvell, B.W. Sintering of dental porcelain: Effect of time and temperature on appearance and porosity. Dent. Mater. 2002, 18, 163-173. [CrossRef]

15. Zhang, Z.; Yi, Y.; Wang, X.; Guo, J.; Li, D.; He, L.; Zahng, S. A comparative study of progressive wear of four dental monolithic, veneered glass-ceramics. J. Mech. Behav. Biomed. Mater. 2017, 74, 111-117. [CrossRef] [PubMed] 